\title{
Adjusting to the ambivalence of nursing home life was explained by the phrase making the best of it
}

Kahn DL.Making the best of it: adapting to the ambivalence of a nursing home environment. Qual Health Res 1999 Jan;9:119-32.

\section{Question}

How do older adults adjust to the dual nature of a Jewish nursing home environment as both an "institution" and a "home"?

\section{Design}

Interpretative anthropology.

\section{Setting}

A 145 bed Jewish nursing home in the western US.

\section{Participants}

A convenience sample of 21 people (19 women, mean age 85.5 y) who expected to be in the nursing home until they died. All had major health problems and most $(76 \%)$ were unable to walk without assistance. Length of residency ranged from 3 months to 10 years.

\section{Methods}

During the 9 month study period, data were collected using ethnographic interviews and participant observation. Multiple conversational interviews were held with each of the participants (range of 5-18 interviews for each participant) and recorded via audiotape. Analysis of interview transcripts and field notes included multiple readings of the text in multiple ways, identification of categories, grouping of categories into themes, and explication of themes in a narrative text.

\section{Main findings}

Participants articulated a dynamic tension between their feelings about the nursing home as a "home" and as an "institution." They responded to this tension by making the best of it in 4 distinct ways. Firstly, they recognised the ambivalence of the situation by describing the nursing home as a supportive place of shelter and respite and at the same time, as a restrictive institution that symbolised loss and powerlessness. Participants realised that the institutional nature of the nursing home interfered with the process of making it their home, while in another sense they realised that it was their home. Secondly, they downplayed the negative as a strategy to minimise the negative aspects of their situation. Pointing out negative aspects of the environment was seen as undesirable or non-normative behaviour, and those who did were seen as "complainers" or "trouble makers." Participants also felt that dwelling on negative aspects did not help one to make the best of it. Thirdly, they articulated the belief that they had no other options. They understood that nursing home care was needed because of declining physical ability, frailty, vulnerability, and social dependence, and they recognised that other living situations (eg, living with children) were not viable options. Fourthly, they engaged in an active process of making the best of it. They described ways in which they took responsibility for creatively and volitionally making the institutional setting into a home. For example, they focused on changing their perspectives rather than on changing the situation itself. Having a private room was important because it allowed participants to resolve some of the perceived ambiguity of their environment. By personalising their rooms and by shutting the door, they could temporarily reconstruct the institutional setting into a home.

\section{Conclusions}

The process of reconciling the inherent ambiguity of a nursing home as a place of refuge and a place of restriction symbolised these participants' struggle with old age. By making the best of it, they engaged in an ongoing effort to reframe and reconstruct the meaning of their social environment.

Source of funding: National Center for Nursing Research, National Institutes of Health

For correspondence: $\operatorname{Dr} D$ L Kahn, University of Texas at Austin, School of Nursing, Austin, TX 78712, USA.Fax +15124714910.

\section{Commentary}

In this study, Kahn explores how elderly people who were articulate and had relatively good cognitive functioning found meaning in their lives in a nursing home. Although the findings are useful, they should be understood in the context of the study from which they were derived.

The study group had a similar cultural background: Jewish and first or second generation immigrants (European, Russian, or Turkish background), a group possibly supported by a community with similar cultural understandings. The findings tell us about how supportive it can be to live in an institution with people who are culturally similar; however, many nursing homes have populations that are much more diverse. The results were drawn from 21 of 145 residents within a multilevel care setting. Because the reason for selecting this subgroup was not specified, we do not know whether those who participated were the most articulate and cognitively intact residents within this setting and whether their experiences would hold true for patients with more impairment.

As a clinical nurse specialist for residential care, I am aware that although a nursing home is definitely not "home," many residents do well because nurses improve their symptom control and comfort. In my experience, both parts of the ambiguity that Kahn talks about ring true as useful ways to conceptualise the experience of residential care.

Findings like this can help to advance our understanding of this specific population. If residents minimise the negative, then nurses must be careful to ensure that a resident is not needlessly stoic (eg, about pain). The importance of residents talking about their losses and discomforts before making the best of it has been recognised by previous authors, ${ }^{1}$ and reinforces the reasons for nurses to practise active listening. These findings also help us to appreciate the symbolic importance of private rooms and personal possessions. Although their value has been documented by others, ${ }^{2}$ this detailed explanation will help to mobilise nurses in encouraging people to bring their possessions into the residence, in protecting these personal possessions, and in regularly using personal possessions to support individual identity.

Tilly Schalkwyk, RN, MSN Clinical Nurse Specialist Holy Family Hospital Vancouver, British Columbia, Canada

1 Brooke V. How elders adjust. Geriatr Nurs 1989;10:66-8.

2 Holzapfel SK. The importance of personal possessions in the lives of the institutionalized elderly. J Gerontol Nurs 1982;8:156-8. 